\title{
Professional capacity building of researchers, health-care professionals and editors of biomedical journals in the Eastern Mediterranean Region
}

Shaukat Ali Juwaid

Pakistan Journal of Medical Sciences, Karachi, Pakistan (Correspondence to: Shaukat Ali Juwaid: shaukat@pjms.org.pk).

Citation: Jawaid SA. Professional capacity building of researchers, health-care professionals and editors of biomedical journals in the Eastern Mediterranean Region. East Mediterr Health J. 2021;27(3):224-226. https://doi.org/10.26719/2021.27.3.224

Received: 10/09/20; accepted: 04/02/21

Copyright (c) World Health Organization (WHO) 2021. Open Access. Some rights reserved. This work is available under the CC BY-NC-SA 3.0 IGO license (https://creativecommons.org/licenses/by-nc-sa/3.o/igo)

\section{Introduction}

Publishing a quality peer-reviewed medical journal in low- and middle-income countries can be a frustrating experience due to human resources and financial constraints (1). In order to help, guide and assist editors in the Eastern Mediterranean Region, the World Health Organization Eastern Mediterranean Regional Office (WHO/ EMRO) hosted a conference for health science journals at its headquarters in Cairo, Egypt (October 2003), wherein the Eastern Mediterranean Association of Medical Editors (EMAME) was formally established (2-3). WHO/ EMRO played a vital role in the establishment of EMAME and contributed significantly towards its development during the initial years.

Subsequently, a training course for editors in Cairo was organized by WHO/EMRO in 2009 (4), and was followed by a 'train the trainer's' course for editors in the Eastern Mediterranean Region (EMR) at Shiraz University of Medical Sciences, Islamic Republic of Iran, during 14-17 November, 2011, at which one editor from each country in the Region was invited (5). Later courses were organized in Pakistan, Saudi Arabia and the United Arab Emirates, which was also extended to Egypt, Lebanon and the Islamic Republic of Iran.

Currently there are 673 biomedical journals in the Region that are listed in WHO Index Medicus for the Eastern Mediterranean Region (IMEMR), although the actual number of journals may be more (i.e., journals not included in IMEMR). Of these, 488 also have online editions. It includes 144 from Egypt, 273 from the Islamic Republic of Iran, 95 from Pakistan, and 31 from Saudi Arabia, while other countries in the Region also have recognized peer-reviewed journals. (Table 1) (6).

The EMAME Executive Council has organized a number of workshops on medical writing, peer review, publication ethics, and training courses for editors in different countries of the Region. This included a threeday workshop on scientific writing and publishing organized in Dubai in collaboration with the Dubai Health Authority (22-24 June, 2018) and was attended by 64 participants from Gulf Region countries. This was followed by a conference on scientific writing in Riyadh,
Saudi Arabia (10 September 2018), during the Global Health Exhibition/Conference.

WHO/EMRO was also instrumental in organizing a workshop in Alexandria, Egypt, in collaboration with The High Institute of Public Health, as well as a workshop in Beirut, Lebanon, in collaboration with the International Epidemiological Association, and attended by the president of the Association of French Speaking Epidemiologists (ADELF), University of Bordeaux, France.

Upon the request of the Ministry of Health \& Medical Education of the Islamic Republic of Iran, EMAME has been concentrating on research and publication ethics workshops in the country (7).

Table 1 Eastern Mediterranean Region health and biomedical journals (October 2020)

\begin{tabular}{lcc} 
Country & $\begin{array}{c}\text { No. journals } \\
\text { (IMEMR) } \\
\mathbf{n}=\mathbf{6 7 3}\end{array}$ & $\begin{array}{c}\text { No. online } \\
\text { journals } \\
\mathbf{n}=\mathbf{4 8 8}\end{array}$ \\
Afghanistan & 2 & 1 \\
Bahrain & 3 & 1 \\
Egypt & 144 & 57 \\
Iraq & 32 & 18 \\
Islamic Republic of Iran & 273 & 257 \\
Jordan & 9 & 7 \\
Kuwait & 6 & 5 \\
Lebanon & 11 & 8 \\
Libya & 6 & 1 \\
Morocco & 7 & 1 \\
Oman & 3 & 3 \\
Pakistan & 95 & 77 \\
Palestine & 3 & 2 \\
Qatar & 4 & 3 \\
Saudi Arabia & 31 & 26 \\
Sudan & 11 & 7 \\
Syrian Arab Republic & 11 & 3 \\
Tunisia & 9 & 5 \\
United Arab Emirates & 5 & 3 \\
Yemen & 8 & \\
\hline IMEMR= Index Medicusfor the Eastern Mediterranean Region & \\
& & 3 \\
\hline
\end{tabular}


Therefore, WHO/EMRO and EMAME organized a two-day workshop on ethics in scientific writing and journal publishing for more than 25 biomedical journal editors (October 2019) at the Iran University of Medical Sciences, Tehran. The focus was on aligning science journal publishing in the Islamic Republic of Iran with international and regional ethical standards and best practices, and encouraging participants to draw on existing national, regional and international professional networks and resources (7).

\section{Training courses development}

Until a few years ago researchers in the Region had few incentives or recognition in being published. Today, the situation is rapidly changing and publication in quality research journals can credit academic promotion. However, lack of training in the art of medical writing remains a major problem for most new writers and novice researchers, who find it extremely difficult to find good mentors. Likewise, editors of biomedical journals are also faced with numerous problems including poor quality manuscripts, difficulty in finding good and reliable reviewers, lack of familiarity by authors with online submissions systems, and limited human and financial resources (1).

Most EMR biomedical journal editors had previously gained their skills through hands-on experience, since no certificate or diploma courses were in existence in the Region. However, this changed with the suggestion to start a Certificate Course in Medical Journalism during the Eastern Mediterranean Medical Journals Conference (EMMJ4) held in Bahrain in 2008 (8). The Islamic Republic of Iran took the initiative with the introduction of a Master's degree in Medical Journalism at Shiraz University of Medical Sciences in 2009 (9).
Following the EMMJ7 Medical Journals Conference held in Shiraz (2015), it was also decided to start a course in medical journalism at the University of Health Sciences (UHS), Lahore, Pakistan. This initiative resulted in proposals for a certificate in medical editing course, as well as an advanced version, after which following successful completion students would then be eligible to enroll in a Master's degree in Medical Journalism at UHS. The Certificate Course in Medical Editing commenced in 2019 after approval by UHS and was a joint project between the university and the Pakistan Association of Medical Editors (PAME) (10-11). The 6-month course covers scientific writing, copy editing, peer review, production, scientific misconduct, impact factor, publication ethics, Open Access, news and feature writing, and functional English, and is conducted in-classroom and online (blended). Graduates in medicine, dentistry and allied health sciences (i.e. nursing, physiotherapy and pharmacy) are eligible to enroll in the course.

The Advanced Course in Medical Editing is expected to start during 2021, which will also include one week's internship with scientific journals recognized for this purpose by UHS and PAME. Only those who have successfully completed the certificate are eligible for enrollment. The Master's degree in Medical Journalism is expected to be offered 2024 .

It is with immense satisfaction that Pakistan has become the second country in the Region after the Islamic Republic of Iran to have such a course, providing opportunities to health-care professionals who wish to take up medical journalism as a career or who seek an additional qualification. This development is expected to greatly facilitate the improvement in standards of medical journalism and also promote the art of medical writing and scientific publishing in the Region.

\section{References}

1. $\quad$ Problems faced by editors of peer reviewed medical journals. Saudi Med J. 2004;25(Supple 1):447-451

2. Jawaid SA. Birth of Eastern Mediterranean Association of Medical Editors (EMAME). Editorial; Pak J Med Sci. 2004;20(4):279-282.

3. Proceedings of first regional conference on medical journals publishing organized by WHO EMRO at Cairo, Egypt in October 2003. Pak J Med Sci. 2003;19(4):330-333.

4. Tim Albert Training (https://www.timalbert.co.uk/training/about-tim-albert-training/, accessed 17 October, 2020).

5. Handjani F. Medical Editors should now concentrate on improving the quality and contents of their journals. The Free Library (https://www.thefreelibrary.com/Medical+Editors+should+now+concentrate+on+improving+the+quality+and...-a0274873285, accessed 20 October, 2020).

6. World Health Organization Regional Office for the Eastern Mediterranean (WHO/EMRO). IMEMR journals directory by country. Cairo: WHO/EMRO; 2020 (http://www.emro.who.int/e-library/imemr/imemr-journals-directory-by-country.html, accessed 17 October, 2020).

7. EMAME Secretary Report (http://www.emro.who.int/images/stories/emame/emame-secretary-report.pdf?ua=1, accessed 19 October, 2020).

8. Jawaid SA. Lessons learnt at Eastern Mediterranean Medical Journals Conference (EMMJ4) at Bahrain. (Editorial) Pak J Med Sci. 2008;24(6):769-71.

9. Shiraz University of Medical Sciences. Medical journalism (https://www.mastersportal.com/studies/195085/medical-journalism. html, accessed 19 October, 2020). 
10. Jawaid SA, Jawaid M. Professional capacity building of Health Science Journal Editors. Pak J Med Sci. 2019;35(4):879-881 https:// doi.org/10.12669/pjms.35.4.1299

11. Certificate in Medical Editing. University of Health Sciences, Lahore, Pakistan. (http://www.uhs.edu.pk/cme.php, accessed 4 August, 2020. 